\title{
28 Research Suare \\ Experimental And Numerical Studies of Shrinkage and Sink Marks On Injection Molded Polymer Gears
}

\author{
Bikram Solanki \\ PDPM IIITDM Jabalpur
}

Hapreet Singh ( $\square$ hps.dme@gmail.com )

PDPM IIITDM Jabalpur

\section{Tanuja Sheorey}

PDPM IIITDM Jabalpur

\section{Research Article}

Keywords: Gear, Injection molding, Polypropylene, Shrinkage, Sink marks, Precision

Posted Date: May 26th, 2021

DOI: https://doi.org/10.21203/rs.3.rs-421891/v1

License: (1) This work is licensed under a Creative Commons Attribution 4.0 International License.

Read Full License 


\section{Abstract}

Injection molding is an efficient and most economical process employed for the mass production of plastic gears and helps to reduce the processing time and cost required to produce the desired geometry. However, significant process and product qualification of plastic gears face the shrinkage and sink marks issues during cooling and after ejection. In present work, the best gate locations and flow resistance analysis along with a polypropylene (PP) were carried out using Autodesk Moldflow Insight 2019.05. The numerical and experimental study was conducted to evaluate the effect of packing pressure, packing time, and melt temperature on diametric shrinkage, mass, and sink marks of PP gear. The results show that by increasing packing pressure and packing time, the diametric shrinkage decreased but mass increased. However, as the melt temperature increased the diametric shrinkage also increased but the mass decreased. The minimum diametric shrinkage of $0.562 \%$ was found in numerical analysis and $1.619 \%$ found in an experimental analysis at the same injection molding process parameters. Mostly, the sink marks were observed in the gear surface between hub and dedendum circle.

\section{Introduction}

The transfer of speed and torque is the prime considerations in any transmission system. Undoubtedly, gear is the most important component in an automobile transmission system, which should work properly and continuously. Generally, conventional metallic gears are used in the transmission system. However, these gears are being replaced by polymer gears for lightweight power transmission. Since, these gears can reduce the mass by $70 \%$, inertia by $80 \%$ and fuel consumption by $9 \%[1]$. Moreover, polymer gear reduces the transmission system weight, cost, lubrication, noise, and improves corrosion resistance, accuracy, efficiency and design[2]. Due to this, the utilization of these gears is increasing in the automobile, household, food, and textile industries[3]. The injection molding (IM) process is one of the most important manufacturing process to produce polymer products. This process converts the polymer pellets to the finished components. Which pertain to excellent surface roughness[2], low production time, low cost, superior dimensional and profile accuracy. However, IM polymer part undergoes shrinkage during cooling and after the ejection stage. The Shrinkage is a contraction in the cavity size of the injection molded part, when undergoes the cooling stage. If the reduction in the size of the component is greater than the acceptable tolerance limit of the part, it causes a huge loss to the manufacturer. Therefore, the minimization of shrinkage is prominent. The polymer shrinkage is influenced by part material, part geometry, fillers content and IM processing parameters such as melt temperature, mold temperature, packing pressure, injection pressure, packing time, injection time and cooling time[4-7]. The shrinkage in PP polymer is mostly influenced by packing pressure, and mold temperature but cooling time and packing time also have lower contribution[8]. The addition of fillers like coir fibers can also improve the PP specimen shrinkage. This is due to the difference in the density of the crystalline phase in unfilled PP and fiber filled PP [9]. To reduce the analysis time and cost the Taguchi method is used. This method provides a robust design of experiments. Which helps to find the best set of processing parameters combination and fiber content. Further, the ANOVA method is applied for the significance analysis of 
different processing parameters [10, 11]. Huang et al.[4] have numerically analyzed the filling of PC-SD card and observed that a thick portion of card fills easily than a thin portion due to lower shear stress between the flow front and card wall. The polymer possesses low thermal conductivity. Therefore, the part surface cools easily while the core remains hot. This semisolid or molten core gets enough time to achieve a highly oriented structure and causes the part to shrink more. With the continued cooling the core heat transfer through a solidified outer surface of parts which acts as a barrier in heat transfer. Due to non-uniform temperature distribution between the core and skin of parts, induces the compressive stresses at the skin and tensile stresses at the core[5]. Mehat et al. [6] observed that the blending ratio had the highest contribution of $56 \%$ on gear shrinkage, which was followed by mold temperature of $24.1 \%$ and cooling time of $10.6 \%$. Wang et al. [7] have analyzed the effect of IM processing parameters on the shrinkage of POM micro gear. The gear was manufactured using Taguchi L18 OA and minimum shrinkage of 0.06 was obtained at an optimum process parameter. The packing time was found as the most influenceable parameter with a significance of $32.47 \%$ on gear shrinkage, which was followed by an injection speed of $22.34 \%$ and a packing speed of $17.3 \%$. Taifor et al. [10] have optimized IM processing parameters and gates number to minimize shrinkage, weld line, warpage, and air traps found for/in ABS gear. They observed that the volumetric shrinkage increased as melt temperature increased but it decreased as the packing pressure and mold temperature increased. The maximum shrinkage of $10.337 \%$ and minimum shrinkage of $8.1879 \%$ was found at melt temperature of $240^{\circ} \mathrm{C}$ and $200^{\circ} \mathrm{C}$ respectively. Bhirud et al.[11] have optimized the IM processing parameter to minimized shrinkage of general-purpose polystyrene (GPPS) refrigerator tray. The tray shrinkage was reduced by $29.9 \%$. The processing parameters such as the mold temperature had the highest percentage contribution of $80.5 \%$ on tray shrinkage followed by melt temperature of $4.89 \%$, packing pressure of $4.73 \%$, injection time of $2.9 \%$ and cooling time of $0.005 \%$. Raz et al. [12] have analyzed the influence of pressure and cycle time on the quality of HDPE spoiler. It was observed that due to smaller cooling time; the ejection temperature of the part may be higher than the required. This may encourage part to shrink more. Longzhi et al. [13] studied the influence of IM processing parameters on sink marks of the automobile dashboard made from Taiwan PP. It was found that melt temperature has the highest significance on sink marks. The best sink mark index of 2.503 found at a melt temperature of $220^{\circ} \mathrm{C}$, mold temperature of $45^{\circ} \mathrm{C}$, injection time of $3 \mathrm{~s}$, holding pressure of $45 \mathrm{MPa}$ and cooling time of $30 \mathrm{~s}$. The main aim of present work is to design and develop an experimental and numerical study of spur gear, and identify the influence of injection molding processing parameters such as packing pressure, packing time and melt temperature on shrinkage, sink marks, mass and water absorption of PP spur gear.

\section{Methodology}

\subsection{Gear material}

Polypropylene (PP) is a widely used semi crystalline polymer, which imparts high tensile strength to weight ratio, excellent chemical inertness, resistance to moisture[14], superior fatigue life and low density[15]. Therefore, PP (M108, Haldia Petrochemical Ltd) was selected as a polymer material for spur 
gear. The PP granules having a spherical shape and diameter of $3.0 \mathrm{~mm}$ to $4.5 \mathrm{~mm}$ (Fig. 1 (a-b)) and their properties are/were given in Table 1.

Table 1

Properties of polypropylene Polymer[16]

\begin{tabular}{|l|lll|}
\cline { 2 - 4 } & Property & Value & Unit \\
\hline Density $\left(23^{\circ} \mathrm{C}\right)$ & 0.90 & $\mathrm{~g} / \mathrm{cm}^{3}$ \\
Melt flow rate $\left(2.16 \mathrm{~kg} \& 230^{\circ} \mathrm{C}\right)$ & 8 & $\mathrm{~g} / 10 \mathrm{~min}$ \\
\hline Heat Deflection Temperature $(0.455 \mathrm{MPa})$ & 94 & ${ }^{\circ} \mathrm{C}$ \\
\hline & Vicat softening temperature $(10 \mathrm{~N})$ & 152 & ${ }^{\circ} \mathrm{C}$ \\
\hline
\end{tabular}

In the present study, the involute profile of spur gear was selected to produces a 3D CAD model using Solidworks 2014. The gear had a module of $3 \mathrm{~mm}$, number of teeth 12, pressure angle of $20^{\circ}$ and teeth width of $10 \mathrm{~mm}$ (Fig. 2 (a)). Keyway of dimensions $10 \mathrm{~mm} \times 3 \mathrm{~mm} \times 2 \mathrm{~mm}$ was provided to fix the gear with a hub of $12 \mathrm{~mm}$ diameter.

\subsection{Gate Location}

The gate location analysis for spur gear was carried out to find the most suitable area, where gates could be located to easily fill the cavity. In this analysis, "the gate region locator" and "advance gate locator" algorithm is used to find the "best gate location" and "flow resistance indicator" results. Which determine the best region to locate the desired number of gate having minimum flow resistance. The Autodesk Moldflow insight ultimate 2019.05 software was used for current study. The "best gate locations" result shown in Fig. 3 (a) and these gate locations were mostly observed at the gear hub area and some at the tooth space on dedendum circle. However, locating the gate in the hub area was difficult to manufacture and the gate could not be located on tooth space as it might harm the involute profile of a gear. Solanki et al. has analysed the gates location and gate number for spur gear and suggested to locate four number of gate [17]. Therefore, four numbers of gates were decided to locate. Further, "flow resistance indicator" analysis was carried to find out the four gate locations having minimum flow resistance and these results were shown in Fig. 3 (b). The minimum flow resistance was found at the teeth surface and in the hub area. But locating the gates in teeth surface may leave some impressions. This can decrease the surface finish and affect the profile accuracy of gear. Similarly, locating the gate in hub area increase the mold cost. Therefore, the surface between hub circle and dedendum circle was chosen to locate the four number of gates as it offers better gate location results and lower flow resistance.

\subsection{Specimen mold}

A single cavity gear mold made of P-20 tool steel was precisely manufactured at CIPET, Bhopal (Fig. 4). The mold is equipped with four gates surface injection system and four pins symmetric ejection systems. 
The circular sprue of length $50 \mathrm{~mm}$, inlet diameter of $5 \mathrm{~mm}$ and outlet diameter of $6 \mathrm{~mm}$ was fabricated to deliver the molten polymer from the machine nozzle to the runner. The four semicircular runners of dimensions $4 \mathrm{~mm} \times 1.5 \mathrm{~mm} \times 1 \mathrm{~mm}$ were provided to supply the polymer from the sprue nozzle to the gates. Similarly, the four semicircular gates of dimensions $2 \mathrm{~mm} \times 0.5 \mathrm{~mm} \times 0.5 \mathrm{~mm}$ were provided to fill the specimen cavity. In addition to this, two vents of dimensions $59 \mathrm{~mm} \times 3 \mathrm{~mm} \times 0.05 \mathrm{~mm}$ were provided to exhale the air from cavity to environment. Moreover, two symmetric cooling channels having an internal diameter of $10 \mathrm{~mm}$ and a length of $160 \mathrm{~mm}$ were designed to cool the mold.

\subsection{Process Parameters}

In this study, three IM processing parameters were varied and other parameters were fixed. The reference value of varied processing parameters was taken from the material datasheet[16]. The typical values of these parameters are given in Table 2.

\begin{tabular}{|c|c|c|c|c|c|c|c|c|c|}
\hline Varied parameter & & & & & & & Fix parameter & & \\
\hline \multirow[t]{2}{*}{ Parameter } & \multirow[t]{2}{*}{ Unit } & \multicolumn{5}{|c|}{ Level } & Parameter & Unit & value \\
\hline & & 1 & ॥ & III & IV & V & Mold temperature & ${ }^{\circ} \mathrm{C}$ & 15 \\
\hline Packing pressure & $\mathrm{MPa}$ & 35 & 70 & 105 & 112 & 126 & Injection time & $s$ & 1 \\
\hline Packing time & $s$ & 5 & 10 & 30 & & & Cooling time & s & 10 \\
\hline Melt temperature & ${ }^{\circ} \mathrm{C}$ & 200 & 230 & 260 & & & Air temperature & ${ }^{\circ} \mathrm{C}$ & 25 \\
\hline
\end{tabular}

\subsection{Experimental Setup}

The polymer processing laboratory was equipped with Ferromatik Milacron Hydron Servo - 150, IM machine (Fig. 5(a)). This could be operated in manual, semiautomatic and fully automatic mode. This laboratory had a chiller unit to supply coolant water for the efficient cooling of the mold. For this study, the IM machine had been operated in a semiautomatic mode to produce gear specimens.

\subsection{Shrinkage Measurement}

The gear shrinkage is a ratio of the difference in addendum circle diameter of cavity and gear to addendum circle diameter of the cavity. The addendum circle diameter of the cavity and gear was measured by the digital vernier (CD-6" CSX) caliper of Mitutoyo Corporation Japan, which is shown in Fig. 5 (b). The gear mass was measured by an analytical balance of Contech instruments Ltd.

\section{Shrinkage (\%) $=\left\{\frac{D_{C}-D_{G}}{D_{C}}\right\} \times 100$}

Where $D_{C}$ and $D_{G}$ were addendum circle diameter of cavity and gear respectively. 


\subsection{Numerical model}

Spur gear geometry was imported as a model for numerical analysis. Four semi-circular runners and gates were provided between hub circle and dedendun circle to inject polymer. The circular cross section of sprue, which offers minimum surface area was designed to reduce the heat loss from polymer to the mold. The mesh type used was "mixed 3D mesh". Figure 2 (b) shows gear mesh with feed system. This gear model consists of 162415 solid elements. The four gates and two vents were provided as boundary conditions. The molding analysis was performed using the "Fill-Pack-Cool-Warp" analysis sequence.

\subsection{Water absorption}

The water absorption test was conducted to analyse the hygroscopic characteristic of produced PP gear. Initially, the gear was heated in the hot air oven at $50{ }^{\circ} \mathrm{C}$ for $24 \mathrm{hr}$. Then gear weight was measured using an analytical balance. Further, the heated gear was fully immersed in the distilled water for $24 \mathrm{hr}$. After that, the weight was measured and once again the same process was repeated.

\section{Results And Discussion}

The experimental and numerical results of gear shrinkage and mass are listed in Table 3-5. Simultaneously this table also shows different varying process parameters and their corresponding value at each experiment. The objective of this study was to analyze the effect of packing pressure, packing time and melt temperature on shrinkage, mass and sink marks of PP gear. The obtained solution would have to make a balance between the selected outputs.

\subsection{Shrinkage}

The experimental and numerical study was conducted to analyse the effect of packing pressure, packing time and melt temperature on the shrinkage of PP gear. From Table 3, it was observed that as packing pressure increased from $35 \mathrm{MPa}$ to $126 \mathrm{MPa}$, the gear shrinkage decreased from 2.667-1.953\% experimentally and $3.409 \%$ to 2.2765 numerically. It might be because the cavity pressure was lower than the applied packing pressure, which causes the induction of extra polymer from the nozzle to the cavity side. This increases the density and mass of gear. A similar effect of packing pressure on the polymer part shrinkage had been observed by Fischer et al.[18] and Annicchiarico et al.[19]. Further, as packing time increased from $5 \mathrm{~s}$ to $30 \mathrm{~s}$, the gear shrinkage decrease from 1.953-1.619\% experimentally and $2.276-0.5619 \%$ numerically. The packing time effect on shrinkage and mass is/was presented in Table 4. This might be because gates, runner and sprue were not frozen at $5 \mathrm{~s}$ packing time. Therefore, as the packing time increased, the polymer continued to fill the cavity. This addition of polymer compensates the gear shrinkage which occurs due to simultaneous mold cooling. A similar influence of packing time on shrinkage improvement of the part was observed by Fischer et al.[18] and Annicchiarico et al. [19]. However, by increasing the melt temperature from $200{ }^{\circ} \mathrm{C}$ to $260^{\circ} \mathrm{C}$, the gear shrinkage increased from $1.619-1.786 \%$ experimentally and $0.5619-2.148 \%$ numerically. From Table 5 , it was found that by increasing the melt temperature polymer density decreases, this reduces the polymer mass 
inside the cavity. Which results in increasing the gear shrinkage. A similar result of increasing melt temperature on pp gear shrinkage was observed by Mehat et al.[20]. The minimum gear shrinkage of $1.61 \%$ and $0.56 \%$ was obtained from experimental and numerical analysis at a packing pressure of 126 $\mathrm{MPa}$, packing time of $30 \mathrm{~s}$ and melt temperature of $200{ }^{\circ} \mathrm{C}$.

Table 3 The packing pressure effect on shrinkage and mass

\begin{tabular}{|c|c|c|c|c|c|c|c|}
\hline \multirow{3}{*}{ Experiment } & \multirow{2}{*}{$\begin{array}{l}\text { Melt } \\
\text { temperature }\end{array}$} & \multirow{2}{*}{$\begin{array}{l}\text { Packing } \\
\text { pressure }\end{array}$} & \multirow{2}{*}{$\begin{array}{l}\text { Packing } \\
\text { time }\end{array}$} & \multicolumn{2}{|l|}{ Shrinkage } & \multicolumn{2}{|l|}{ Mass } \\
\hline & & & & Experimental & Numerical & Experimental & Numerical \\
\hline & ${ }^{\circ} \mathrm{C}$ & $\mathrm{MPa}$ & 5 & $\%$ & & $\mathrm{~g}$ & \\
\hline 1 & & 35 & & 2.667 & 3.409 & 6.95 & 7.31 \\
\hline 2 & & 70 & & 2.309 & 2.933 & 7.137 & 7.48 \\
\hline 3 & 200 & 105 & 5 & 2.048 & 2.5 & 7.284 & 7.62 \\
\hline 4 & & 112 & & 2 & 2.438 & 7.324 & 7.64 \\
\hline 5 & & 126 & & 1.953 & 2.276 & 7.394 & 7.69 \\
\hline
\end{tabular}

Table 4 The packing time effect on shrinkage and mass

\begin{tabular}{|c|c|c|c|c|c|c|c|}
\hline \multirow{3}{*}{ Experiment } & \multirow{2}{*}{$\begin{array}{l}\text { Melt } \\
\text { temperature }\end{array}$} & \multirow{2}{*}{$\begin{array}{l}\text { Packing } \\
\text { pressure }\end{array}$} & \multirow{2}{*}{$\begin{array}{l}\text { Packing } \\
\text { time }\end{array}$} & \multicolumn{2}{|l|}{ Shrinkage } & \multicolumn{2}{|l|}{ Mass } \\
\hline & & & & Experimental & Numerical & Experimental & Numerical \\
\hline & ${ }^{\circ} \mathrm{C}$ & $\mathrm{MPa}$ & $\mathrm{s}$ & \multicolumn{2}{|l|}{$\%$} & \multicolumn{2}{|l|}{$\mathrm{g}$} \\
\hline 1 & & & 5 & 1.953 & 2.276 & 7.394 & 7.69 \\
\hline 2 & 200 & 126 & 10 & 1.69 & 2.114 & 7.377 & 7.71 \\
\hline 3 & & & 30 & 1.619 & 0.5619 & 7.367 & 7.71 \\
\hline
\end{tabular}

Table 5 The melt temperature effect on shrinkage and mass

\begin{tabular}{|c|c|c|c|c|c|c|c|}
\hline \multirow{3}{*}{ Experiment } & \multirow{2}{*}{$\begin{array}{l}\text { Melt } \\
\text { temperature }\end{array}$} & \multirow{2}{*}{$\begin{array}{l}\text { Packing } \\
\text { pressure }\end{array}$} & \multirow{2}{*}{$\begin{array}{l}\text { Packing } \\
\text { time }\end{array}$} & \multicolumn{2}{|l|}{ Shrinkage } & \multicolumn{2}{|l|}{ Mass } \\
\hline & & & & Experimental & Numerical & Experimental & Numerical \\
\hline & ${ }^{\circ} \mathrm{C}$ & $\mathrm{MPa}$ & $\mathrm{s}$ & $\%$ & & $\mathrm{~g}$ & \\
\hline 1 & 200 & & & 1.619 & 0.562 & 7.368 & 7.71 \\
\hline 2 & 230 & 126 & 30 & 1.619 & 1.009 & 7.339 & 7.71 \\
\hline 3 & 260 & & & 1.786 & 2.148 & 7.252 & 7.7 \\
\hline
\end{tabular}

\subsection{Sink mark}

From numerical and experimental analysis, the sink marks were mostly found in the gear surface between hub and dedendum circle i.e. at sink zone 1. Some sink marks were also found in the gear teeth surface below pitch circle i.e. at sink zone 2. From Fig. 6 (a), it was observed that in sink zone 1, the gear surface sink more than the sink zone 2, because of more polymer accumulation. In this region top and bottom surface of the gear, which was in direct contact with mold, cooled easily and solidified but the core remained in a molten and semisolid state. As the cooling continued, heat transfer from the core through the solidified outer surface of gears which acted as a barrier since polymer possesses low thermal conductivity. This gave enough time to achieve a highly oriented structure at the core and causes gear surface to sink. Non-uniform temperature distribution between the core and surface of gear, induces 
the compressive stresses at the surface and tensile stresses at the core [4, 5]. These compressive stresses compress the gear surface at zone 1 and produce a concave shape. This can be seen in Fig. 6 (a). However, as long as packing pressure increased from $35 \mathrm{MPa}$ to $126 \mathrm{MPa}$, the magnitude of sink marks decreased in the gear surface. This is shown in Fig. 7 (a). Where concave shape in gear surface was not observed. The maximum sinks marks were found at a packing pressure of $35 \mathrm{MPa}$ and the minimum sink marks were observed at packing pressure of $126 \mathrm{MPa}$. A similar result was found in experimentally manufactured gear. Similarly, Guo et al. [21] have also reported that by increasing the packing pressure, the sink marks depth decreases. However, as long as packing time increased from $5 \mathrm{~s}$ to $30 \mathrm{~s}$, the intensity of sink marks increased slightly in some regions although the overall sink marks affected area decreased numerically in Fig. 8 (b). But no change was observed experimentally in Fig. 8 (a). Furthermore, it was observed that in the numerical analysis as the melt temperature increased from $200{ }^{\circ} \mathrm{C}$ to $230{ }^{\circ} \mathrm{C}$ the sink marks decreased slightly which further increased by increasing the melt temperature from 230 ${ }^{\circ} \mathrm{C}$ to $260^{\circ} \mathrm{C}$. This is shown in Fig. 11. However, experimental outcomes show that there is no change in sink marks observed in the gear surface by increasing the melt temperature.

\subsection{Water absorption}

The water absorption test was carried out and the corresponding results were shown in Table 6. It was found that after $24 \mathrm{hr}$ of immersion, the water absorbed by gear was small. However, no further water was absorbed by the gear when it was immersed for the next $24 \mathrm{hr}$. The maximum $0.014 \%$ of water was absorbed in experiment 1 and 2 , the minimum $0.013 \%$ of water was absorbed in experiment 3 . Moreover, it was also observed that there was no significant influence of increasing the packing pressure from 35 MPa to $105 \mathrm{MPa}$ on water absorbance of gear. Which shows the low water absorbing nature of PP polymer.

Table 6

Showing the water absorption of the gear

\begin{tabular}{|llllll|}
\hline Exp. & $\mathbf{2 4} \mathbf{~ h r}$ Heating & $\mathbf{2 4} \mathbf{~ h r ~ I m m e r s i o n ~}$ & $\mathbf{4 8 ~ h r}$ Immersion & $\mathbf{2 4} \mathbf{~ h r} \%$ & $\mathbf{4 8 ~ h r}$ \\
\hline 1 & 6.922 & 6.923 & 6.923 & 0.014447 & 0 \\
\hline 2 & 7.113 & 7.114 & 7.114 & 0.014059 & 0 \\
\hline 3 & 7.262 & 7.263 & 7.263 & 0.01377 & 0 \\
\hline
\end{tabular}

\section{Conclusions}

The numerical analysis was performed to find the best gate location for symmetric polypropylene gear using Moldflow insight ultimate 2019. Further, the simulation was carried out to investigate the effect of packing pressure, packing time and melt temperature on shrinkage, mass and sink marks of the gear. Finally, the experimental test was done to validate the numerical results. The following conclusions could be drawn: 
- The optimum gate location was found on the hub side surface and tooth space on the dedendum circle.

- The minimum shrinkage of $619 \%$ and $0.562 \%$ was obtained experimentally and numerically at packing pressure of $126 \mathrm{MPa}$, packing time of $30 \mathrm{~s}$ and melt temperature of $200{ }^{\circ} \mathrm{C}$.

- The maximum mass of $7.377 \mathrm{~g}$ and $7.71 \mathrm{~g}$ was also found in experimental and numerical analysis at same set of processing parameters.

- The minimum sink marks were observed at packing pressure of $126 \mathrm{MPa}$, packing time of $5 \mathrm{~s}$ and melt temperature of $200{ }^{\circ} \mathrm{C}$ in numerical and experimental study respectively.

- The variation in processing parameters yield $39.287 \%$ and $83.5 \%$ improvement in the shrinkage in experimental and numerical study

- The minimum amount of $0.013 \%$ water absorbed by the gear, which was produced at packing pressure of $105 \mathrm{MPa}$, packing time of $5 \mathrm{~s}$ and melt temperature of $200{ }^{\circ} \mathrm{C}$.

\section{Declarations}

We confirm that the manuscript has been read and approved by all named authors and that there are no other persons who satisfied the criteria for authorship but are not listed. We further confirm that the order of authors listed in the manuscript has been approved by all of us. We confirm that we have given due consideration to the protection of intellectual property associated with this work and that there are no impediments to publication, including the timing of publication, with respect to intellectual property. In so doing we confirm that we have followed the regulations of our institutions concerning intellectual property.

\section{Funding:}

There has been no significant financial support for this work that could have influenced its outcome.

\section{Conflicts of interest:}

We wish to confirm that there are no known conflicts of interest associated with this publication.

\section{Code availability:}

Not applicable

\section{Author's contributions:}

We confirm that author, Mr.Bikram Singh Solanki, did the experimental work and simulation work and analyzed the results and wrote the manuscript. While, author, Dr.Harpreet Singh and Dr.Tanuja Sheorey helped for analyzing the outcomes and reviewed the manuscript.

\section{Ethics approval:}


We confirm that this manuscript contain the original findings of experimental and numerical study. Further we also confirm that this manuscript neither submitted in any other journal for consideration nor published.

\section{Consent to participate:}

Not applicable

\section{Consent to publication:}

I, the undersigned, give my consent for the publication of identifiable details, which can include photograph(s) and/or videos and/or case history and/or details within the text ("Material") to be published in the above Journal and Article

Bikram Singh Solanki

Harpreet Singh

Tanuja Sheorey

\section{References}

1. Snyder L (2010) At the peek of the Polymer Food Chain. In: Gear Technol. https://www.geartechnology.com/issues/0610x/victrex.pdf

2. Ozdemir A, Uluer O, Guldas A (2004) Flow front advancement of molten thermoplastic materials during filling stage of a mold cavity Flow front advancement of molten thermoplastic materials during filling stage of a mold cavity. Polym Test 23:957-966 . https://doi.org/10.1016/j.polymertesting.2004.04.011

3. Imrek H (2009) Tribology International Performance improvement method for Nylon 6 spur gears. Tribol Int J 42:503-510 . https://doi.org/10.1016/j.triboint.2008.08.011

4. Hung S miao, Jao R yuan, Lin jui chang, Lee K sun (2008) Study of mold design on sd card with 3D mold flow analysis. Key Eng Mater 364-366:629-633 . https://doi.org/10.4028/www.scientific.net/KEM.364-366.629

5. Struik LCE (1978) Orientation Effects and Cooling Stresses in Amorphous Polymers. Polym Eng Sci 18:799-811

6. Mehat NM, Zakarria NS, Kamaruddin S (2018) Optimization of recycled glass fibre-reinforced plastics gear via integration of the taguchi method and grey relational analysis. IOP Conf Ser Mater Sci Eng Pap 318:012061 . https://doi.org/10.1088/1757-899X/318/1/012061

7. Wang M, Arifin F, Huynh TT (2019) Optimization of molding parameters for a micro gear with taguchi method optimization of molding parameters for a micro gear with taguchi method. IOP Conf Ser $\mathrm{J}$ Phys 1167:012001 . https://doi.org/10.1088/1742-6596/1167/1/012001 
8. Mohan M, Ansari MNM, Shanks RA (2017) Review on the Effects of Process Parameters on Strength, Shrinkage, and Warpage of Injection Molding Plastic Component. Polym. - Plast. Technol. Eng. 56:112

9. Tan HS, Yu YZ, Xing LX, Zhao LY, Sun H qing (2013) Density and Shrinkage of Injection Molded Impact Polypropylene Copolymer/Coir Fiber Composites. Polym - Plast Technol Eng 52:257-260 . https://doi.org/10.1080/03602559.2012.745553

10. Taifor MN, Yildirim N (2019) Simulation and optimization of a plastic injection process for manufacture of plastic gears with minimized defects in the product. In: International conference on mathematics-engineering-natural \& medical science. gaziantep, Turkey

11. Bhirud T, Metkar R (2017) Experimentation and optimization of shrinkage in plastic injection molded gpps part. In: Proceedings of the International conference on communication and Ssgnal processing 2016. Lonere,Maharashtra,India, pp 107-112

12. Raz K, Chval Z (2017) Influences of pressures and cycle times on properties of final plastic product from HDPE. In: 2017 International Conference on Mechanical, System and Control Engineering (ICMSC). IEEE, St. Petersburg, Russia, pp 1-5.

13. Longzhi Z, Binghui C, Jianyun L (2010) Optimization of plastics injection molding processing parameters based on the minimization of sink marks. In: 2010 international conference on mechanic automation and control engineering. IEEE, Wuhan, China, pp 1-3.

14. Navin Chand, Hashmi and SAR (2009) The sliding wear of polypropylene and its blends. In: Polymer Tribology. Imperial College Press, London, pp 449-468.

15. Mertens AJ, Senthilvelan S (2015) Durability enhancement of polymer gear using compressed air cooling. J Mater Des Appl 0:1-11 . https://doi.org/10.1177/1464420715581195

16. Halene $P(2014)$ Halene $-P^{*}$, Technical data sheet $M 108$, Haldia petrochemical limited. http://www.haldiapetrochemicals.com/pdf/polypropylene/M108.pdf. Accessed 5 Sep 2020.

17. Solanki BS, Singh H, Sheorey T (2020) Study on gate location and gate number for manufacturability of polymer gears. In: International conference ion recent advancements in mechanical engineering. Springer, Silchar,Assam, India, pp 71-81

18. M.Fischer J (2013) Causes of Molded Part Variation: Processing. In: Handbook of Molded Part Shrinkage and Warpage, Second. Elsevier, pp 81-98

19. Annicchiarico D, Alcock JR (2014) Review of Factors that Affect Shrinkage of Molded Part in Injection Molding. Mater Manuf Process 29:662-682 . https://doi.org/10.1080/10426914.2014.880467

20. Mehat NM, Kamaruddin S, Othman AR (2013) Modeling and Analysis of Injection Moulding Process Parameters for Plastic Gear Industry Application. ISRN Ind Eng 2013:1-10 . https://doi.org/10.1155/2013/869736

21. Guo W, Hua L, Mao H (2014) Minimization of sink mark depth in injection-molded thermoplastic through design of experiments and genetic algorithm. Int J Adv Manuf Technol 1-11 . https://doi.org/10.1007/s00170-013-5603-8

Page $11 / 17$ 
Figures

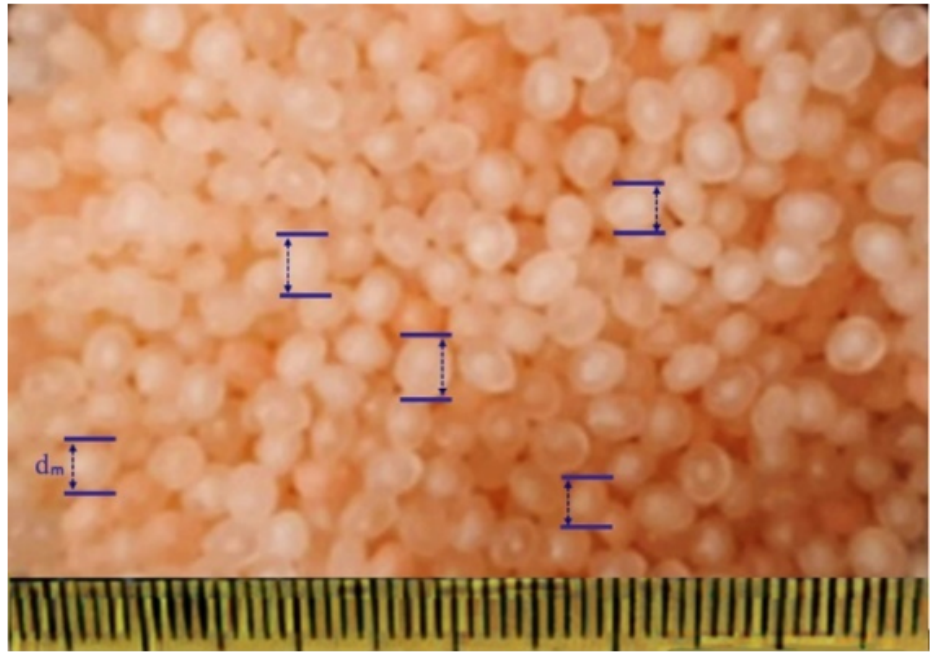

(a)

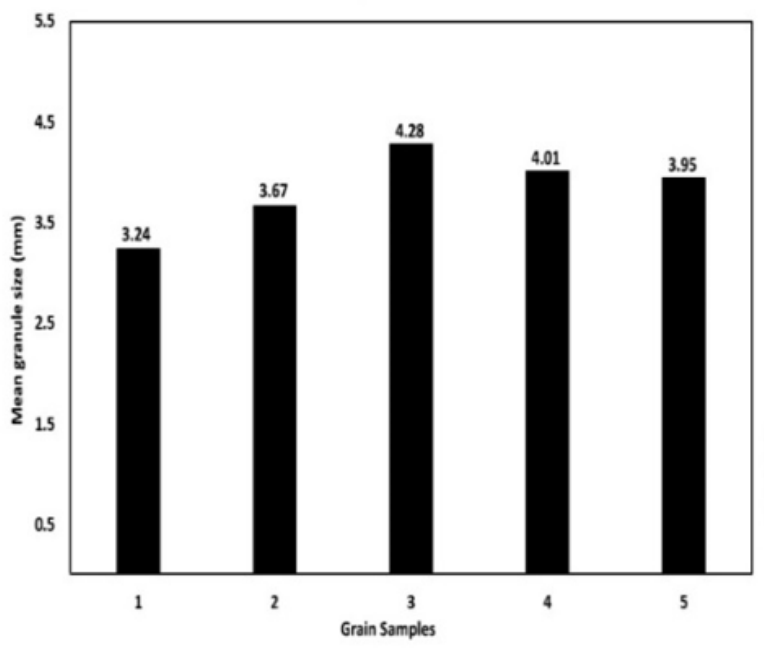

(b)

\section{Figure 1}

(a) Morphology of PP granules (b) mean granule diameter

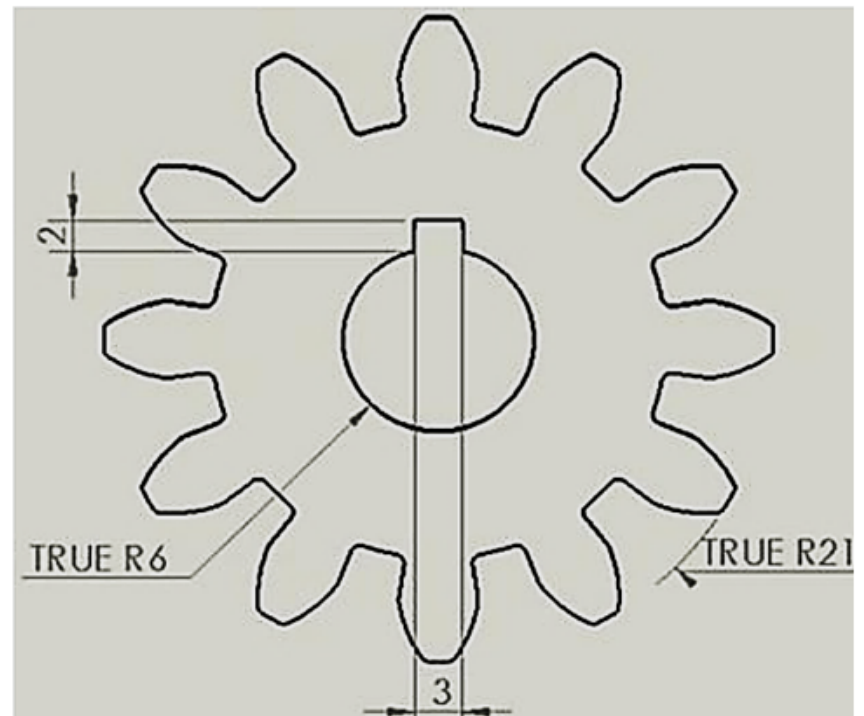

(a)

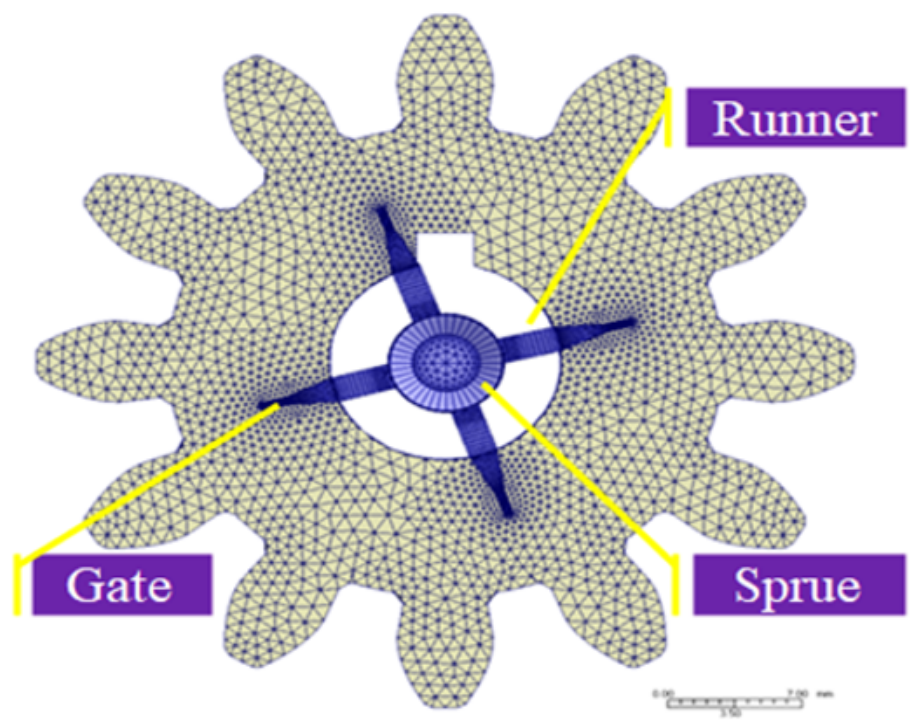

(b)

Figure 2

Spur gear (a) specimen and (b) Gear mesh with feed system 


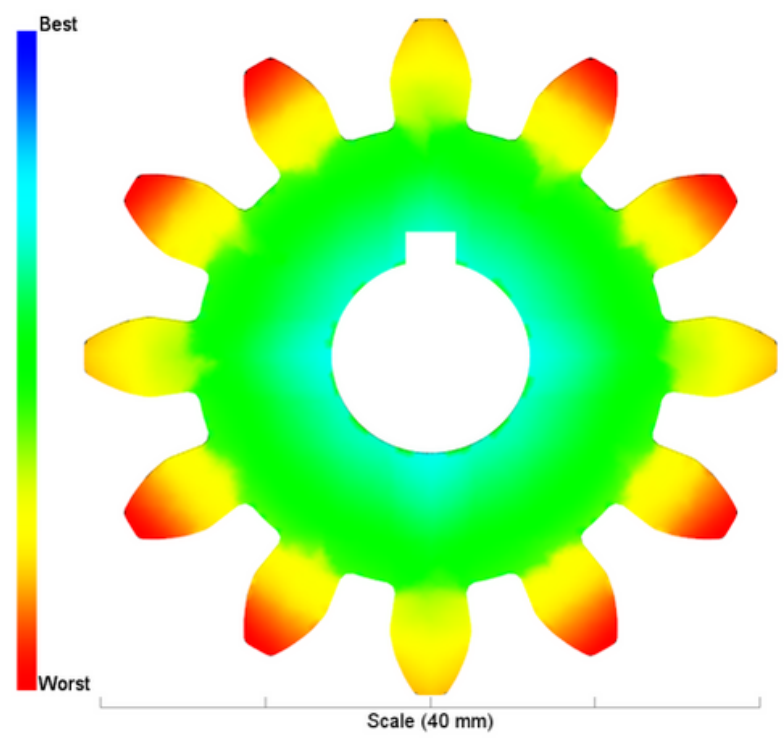

(a)

Figure 3

Gate location: (a) Best gate indicator and (b) Flow resistance indicator

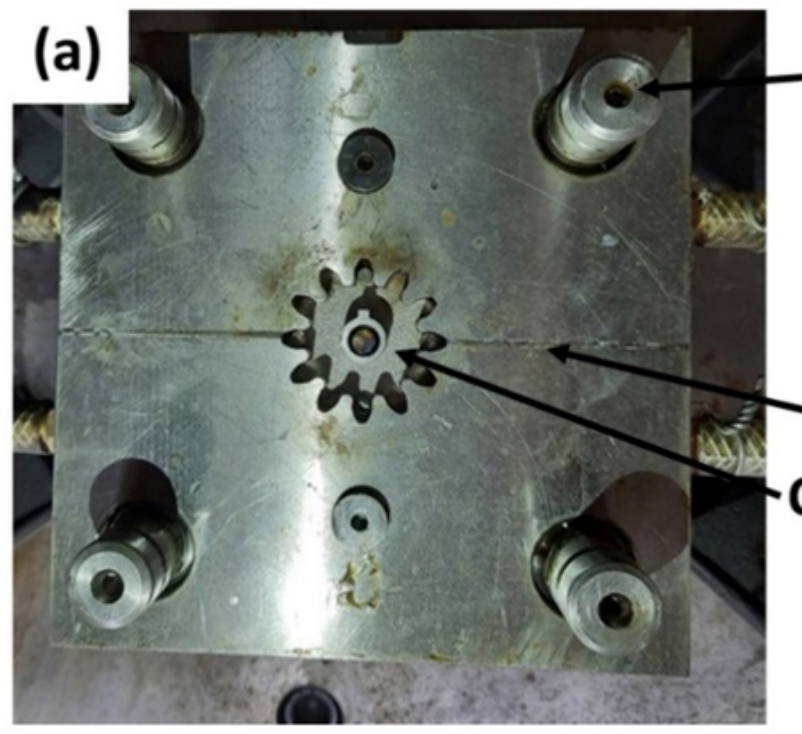

(b)
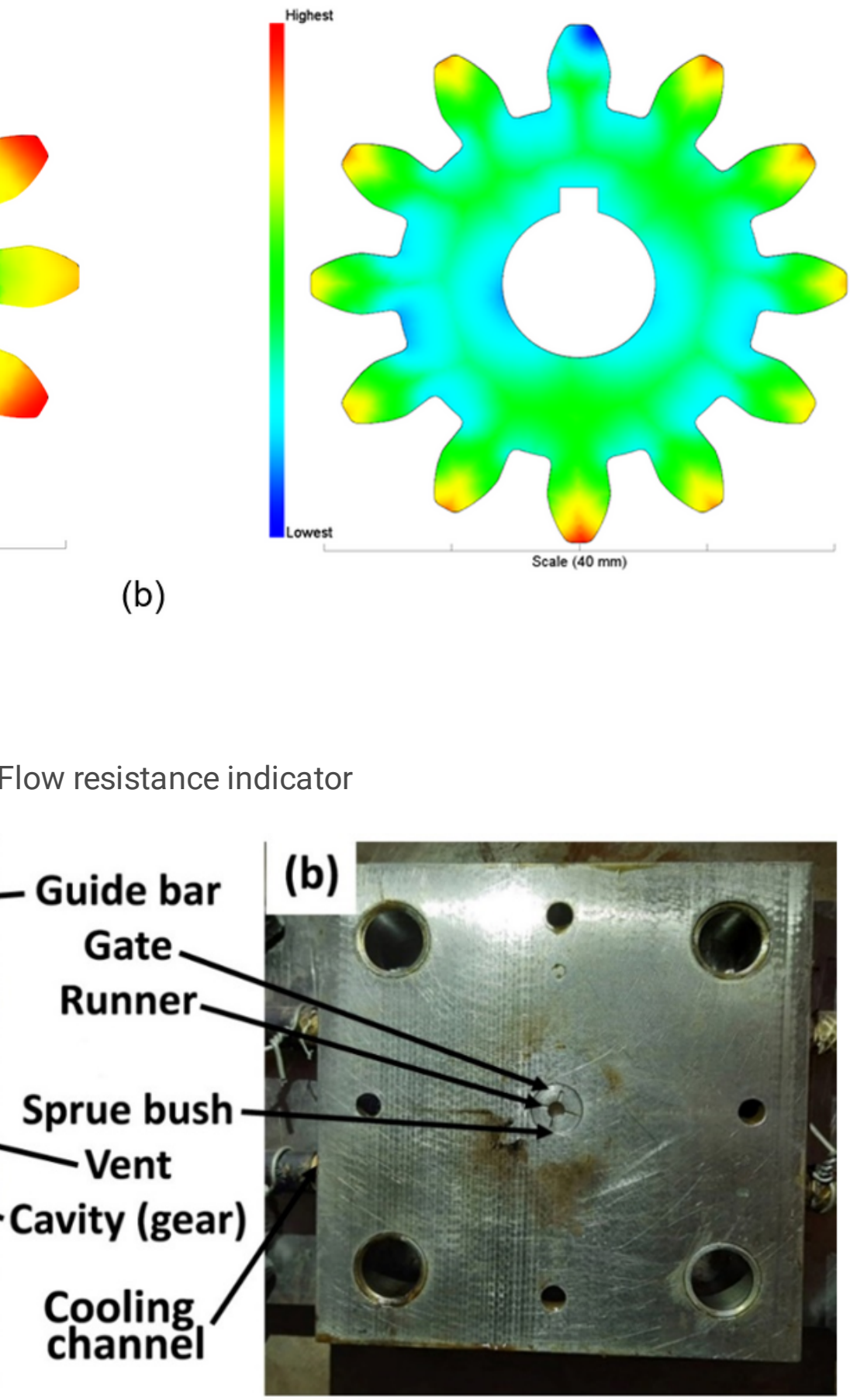

Figure 4

The single cavity gear mold (a) Gear cavity plate (b) Feed system plate 


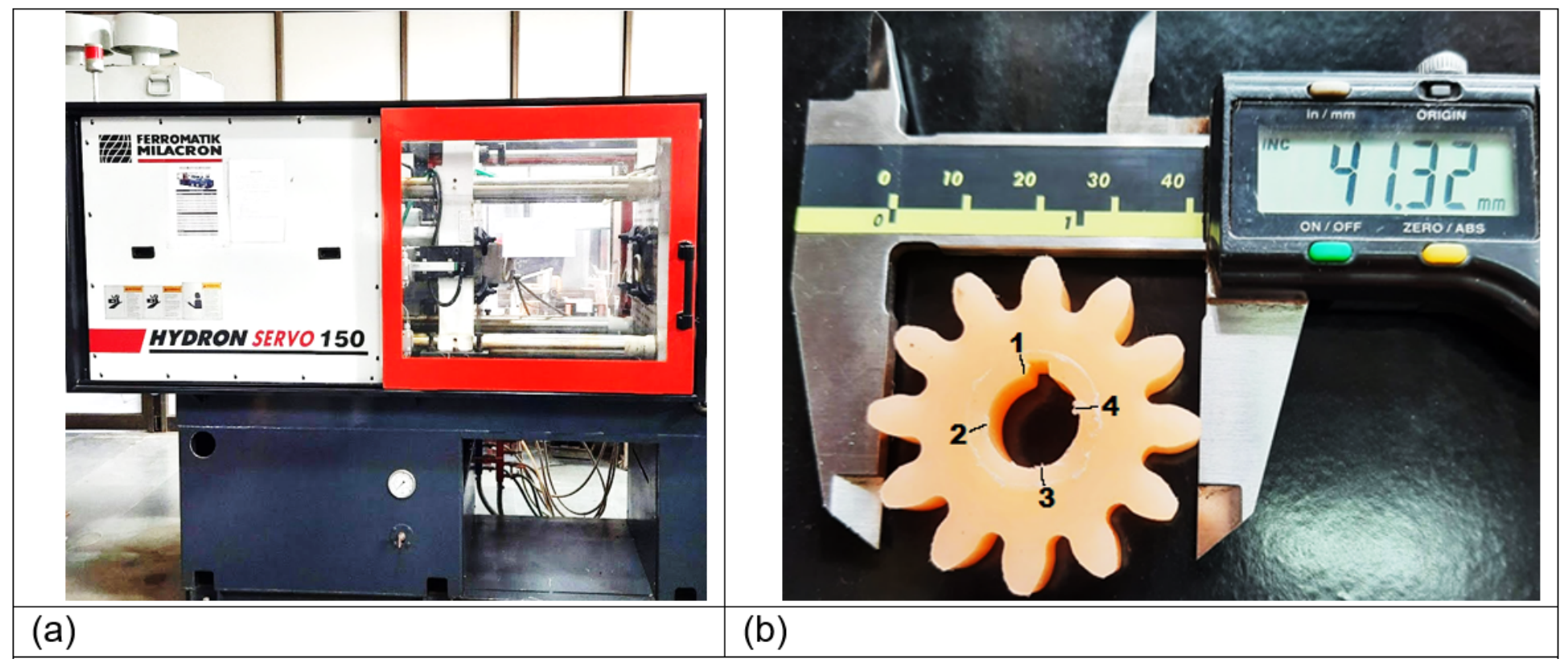

Figure 5

A photographic view of (a) IM machine (b) Gear measurement

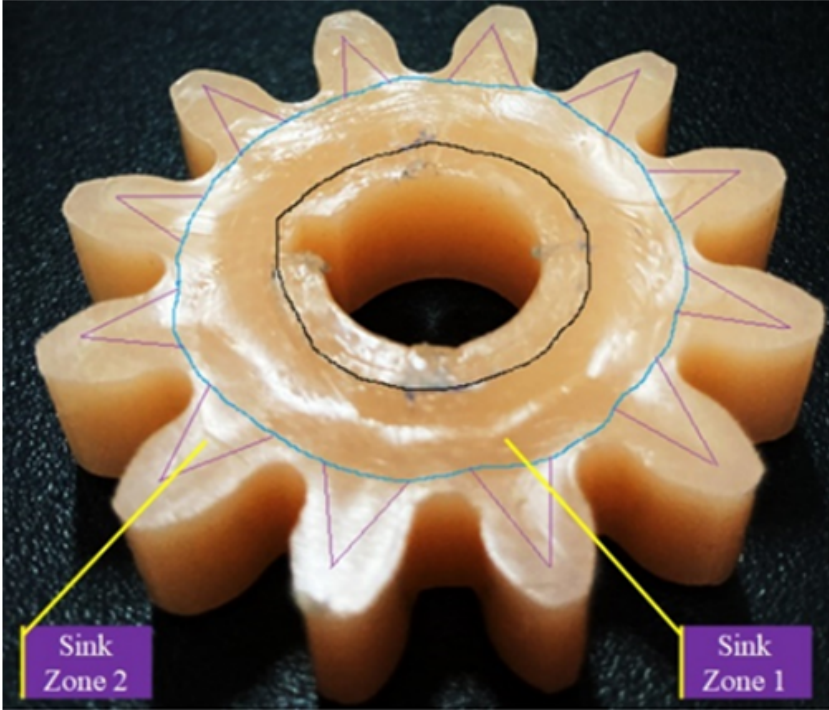

(a)

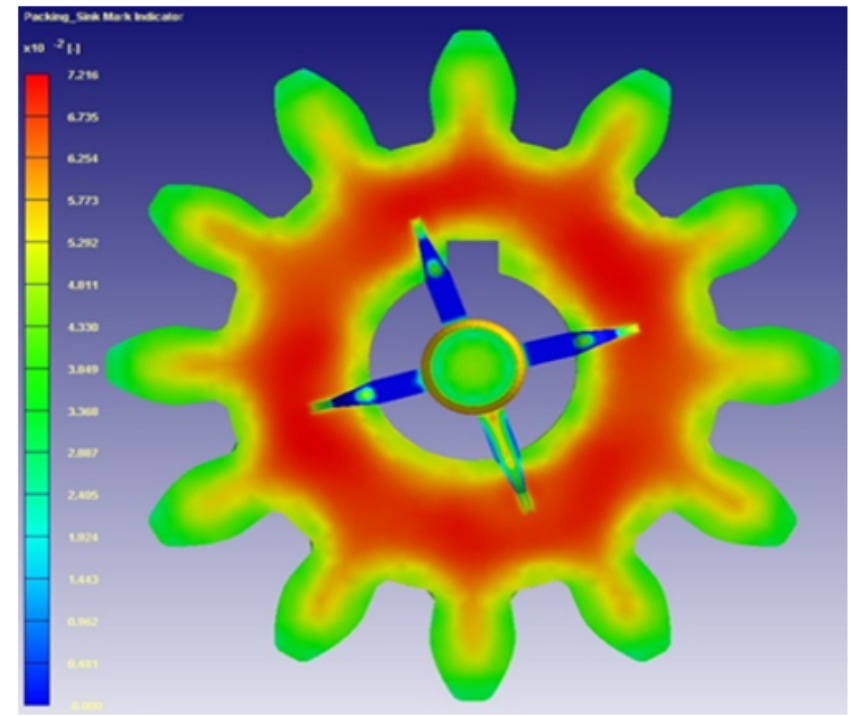

(b)

Figure 6

The sink marks at $35 \mathrm{MPa}$ packing pressure in gear (a) Experimentally produced and (b) Numerically produced 


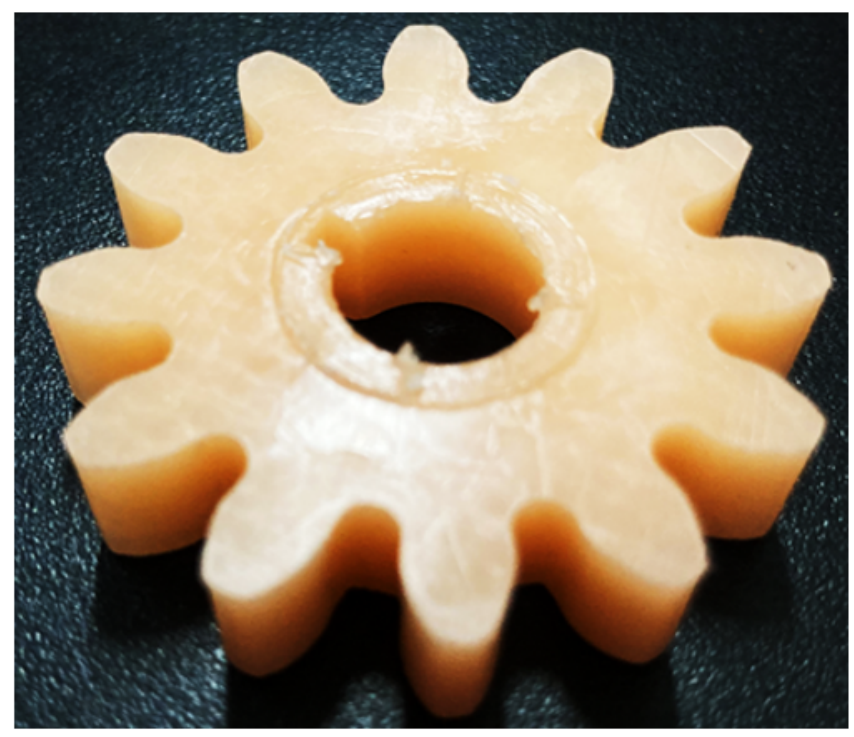

(a)

\section{Figure 7}

The sink marks at $126 \mathrm{MPa}$ packing pressure in gear (a) Experimentally produced and (b) Numerically produced

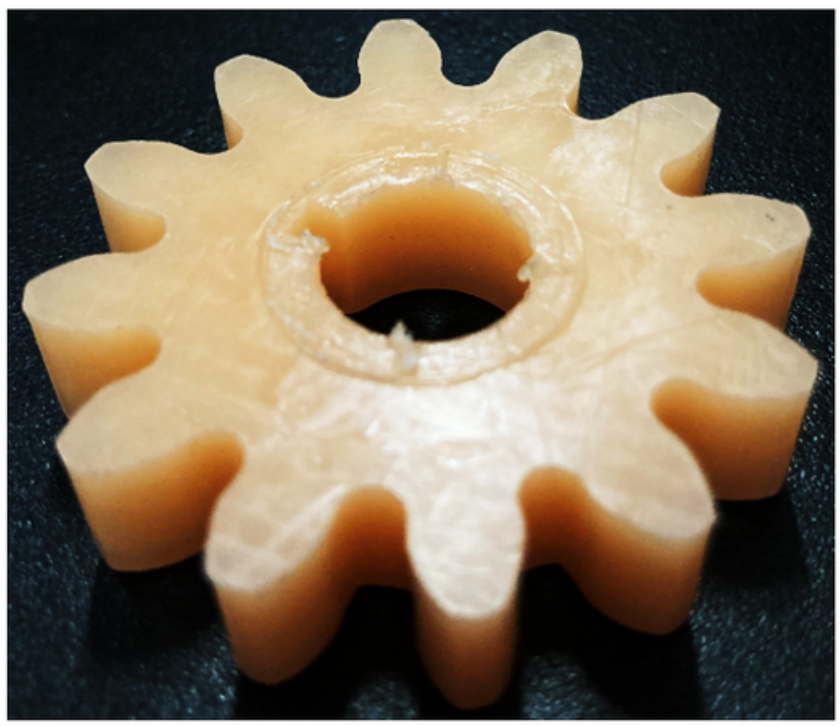

(a)

(b)

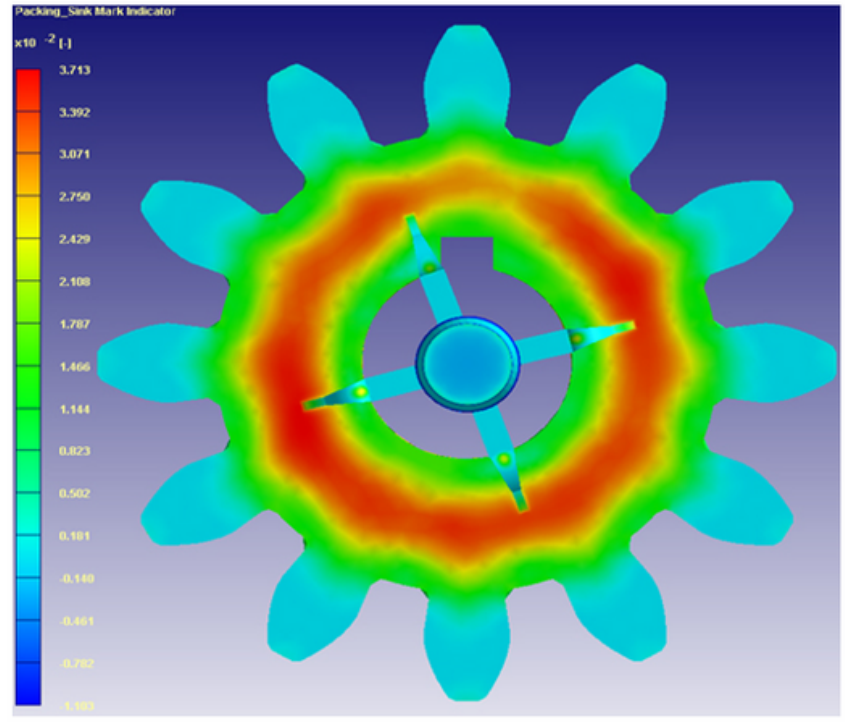

(b)

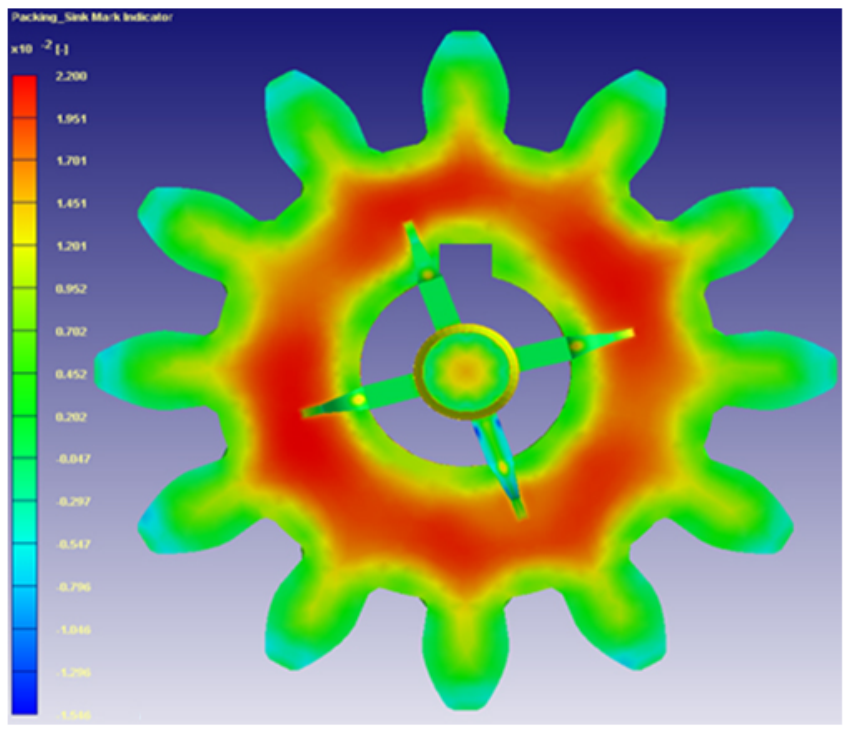




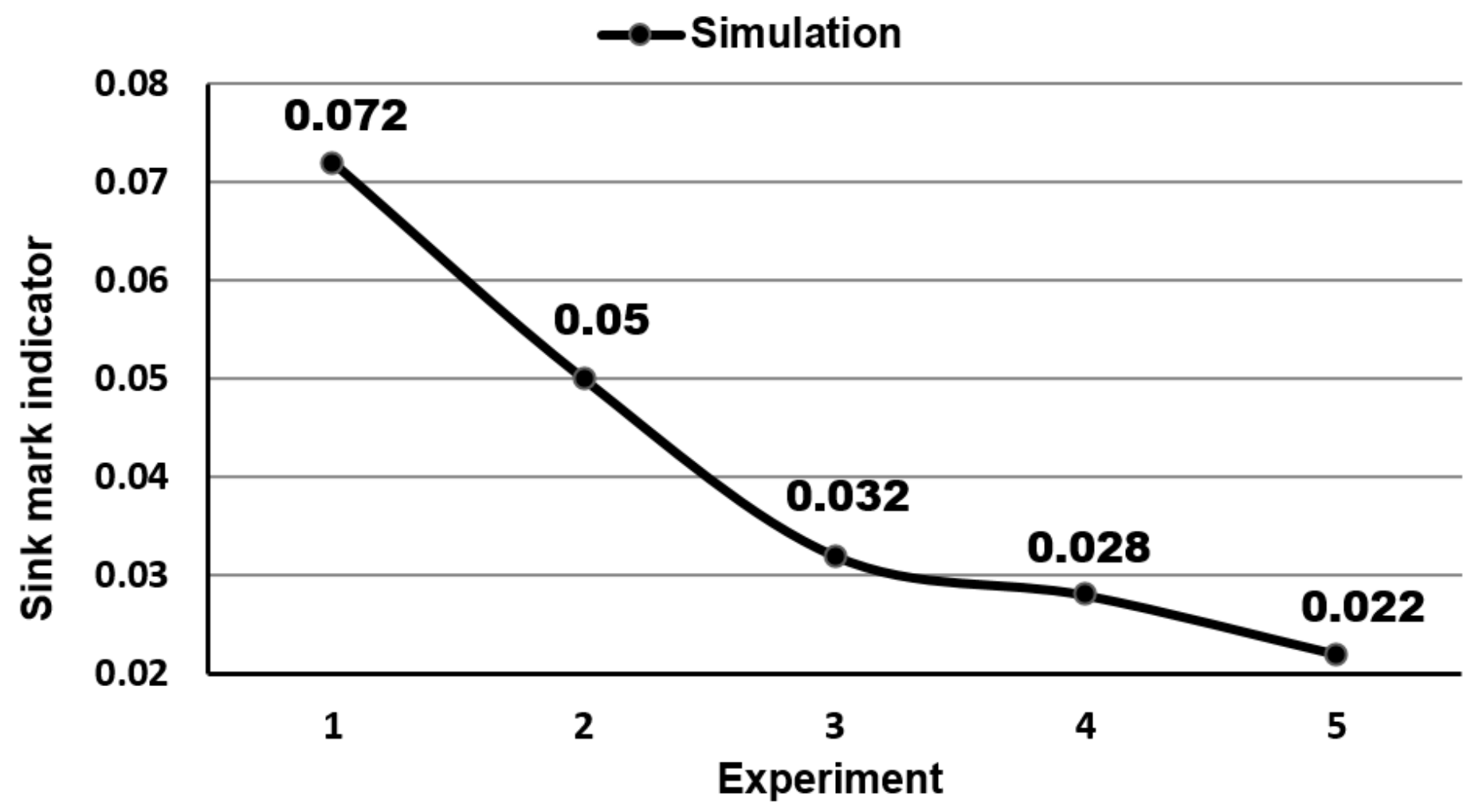

Figure 9

Effect of packing pressure on sink marks indicator

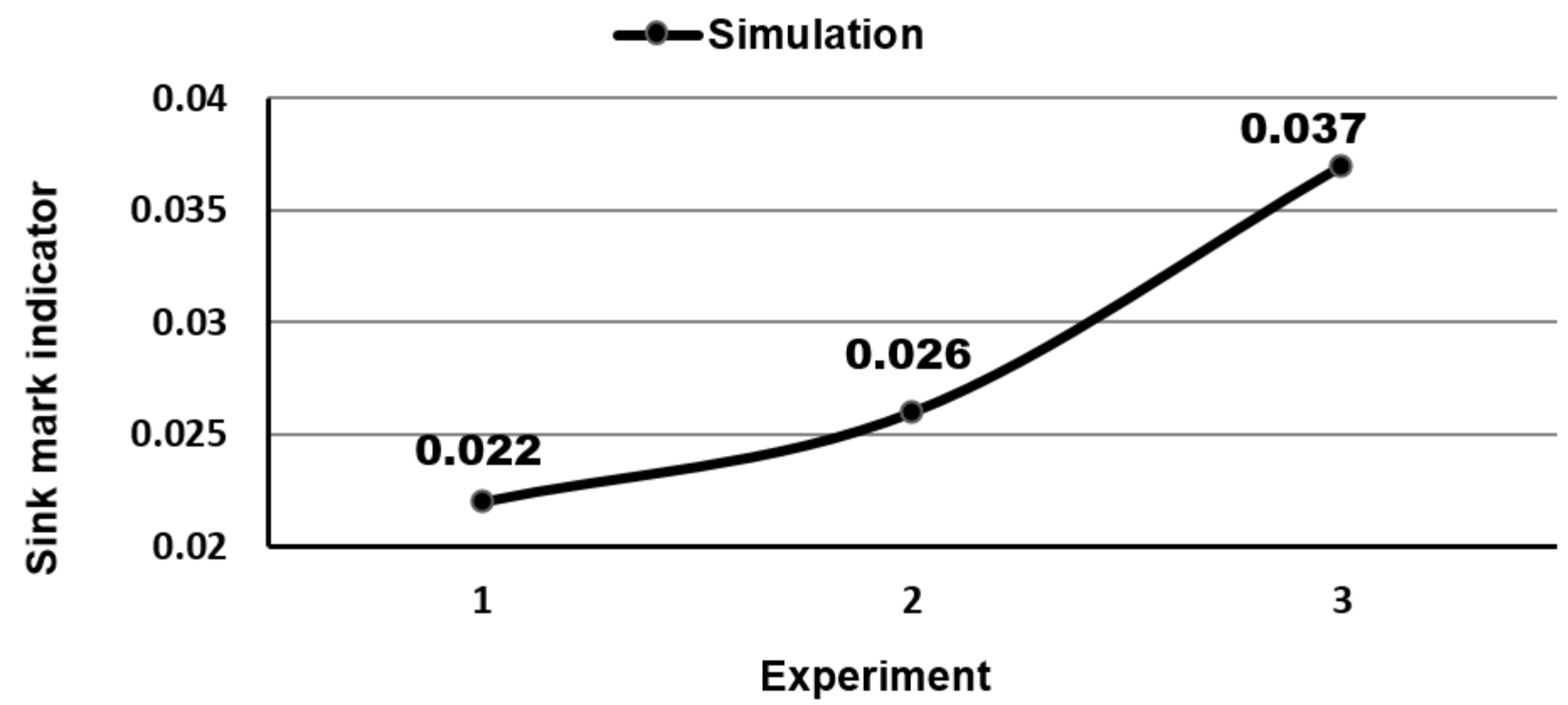

Figure 10

Effect of packing time on sink marks indicator 


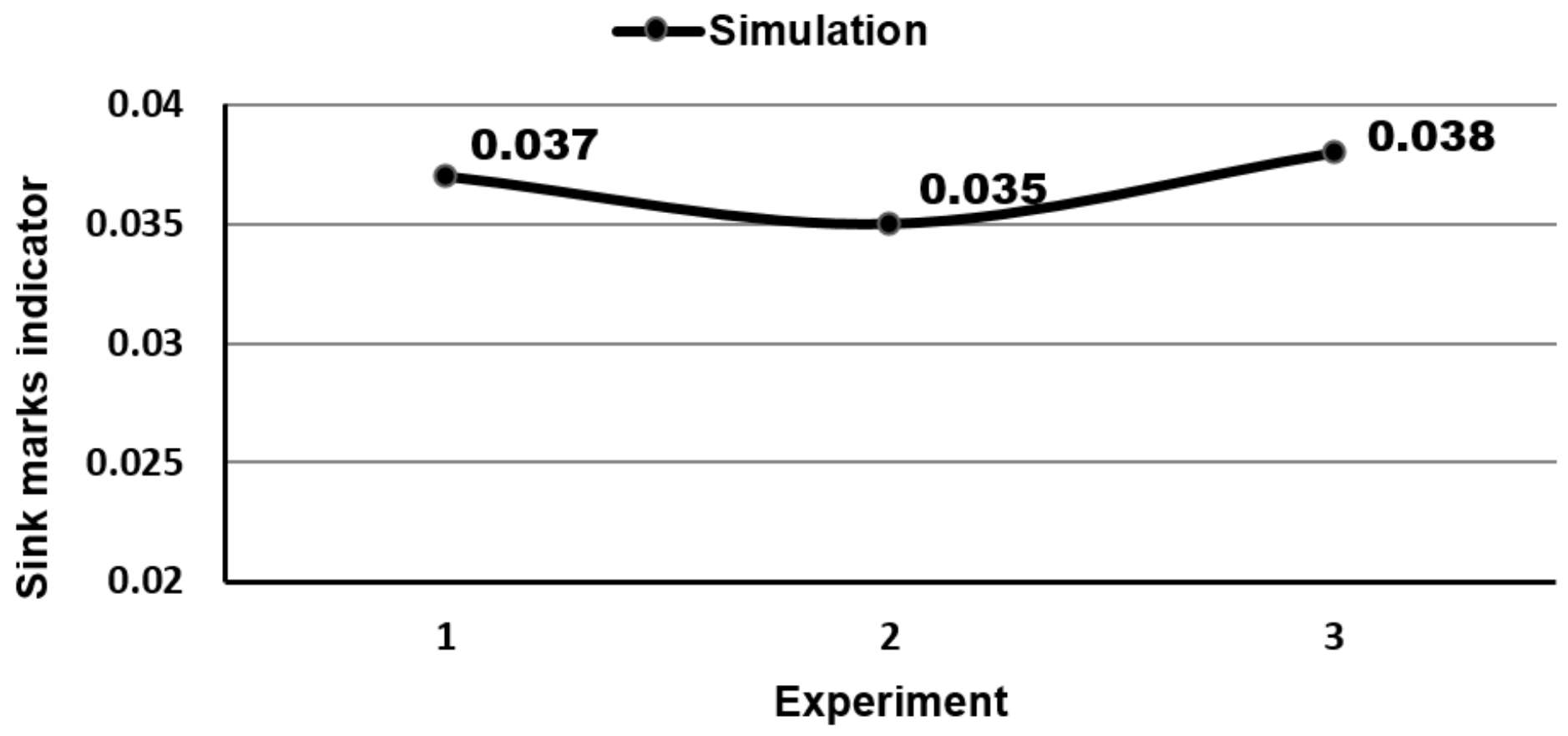

Figure 11

Effect of melt temperature on sink marks indicator 